\title{
Azathioprine pulse therapy to prolong remission of psoriasis
}

\author{
Ramji Gupta* \\ Consultant Dermatologist, Department of Dermatology, Indraprastha Apollo hospital, Sarita Vihar, New Delhi- 110076, India
}

\begin{abstract}
Psoriasis, a common disease with variable clinical manifestation effect the quality of life. Prevalence of psoriasis varies from country to country, effect equally to male and female and all age groups. Pathogenesis of psoriasis seems to be genetically determined T-lymphocyte mediated disorder due to interaction between keratinocytes and lymphocytes.

Various treatments used for treating psoriasis topical or systemic, clear the psoriasis lesions partially or completely, but are not able to produce prolong or permanent remission. Maximum remission period reported with all the known therapies are 1 year. Chief problem with all the therapies are relapses.

Recently introduced azathioprine pulse therapy has been found to target specially to activated T-lymphocytes leading to long term remission and less organ toxicity. In this treatment azathioprine was used as intermittent high dose (IHD) i.e. $500 \mathrm{mg}$ daily on 3 consecutive days repeated every month with continuous low dose azathioprine (CLD) $100 \mathrm{mg}$ daily in between the IHD. It was divided into four phases. In phase I, treatment with IHD and CLD was continued till all the lesions of psoriasis clear. Methotrexate (MTX) $15-25 \mathrm{mg}$ orally or subcutaneously weekly along with coal tar $6 \%$ was also given to clear the lesions fast. After all lesions clear patients enter into phase II where all the treatment is stopped except IHD and CLD which was given for 9 months to prevent any minor recurrence. At the end of 9 months if no recurrence occur IHD was stopped and patients take only CLD for another 9 months (Phase III). In phase IV CLD was also stopped and patients were followed up for any recurrence.
\end{abstract}

With this therapy about 70 patients inter into phase IV i.e. remission for 1-10 years continuously after all treatment was stopped. Subsequently it was found clearing the psoriatic arthritis and nail changes in psoriasis also for prolonged period.

\section{Introduction}

Psoriasis a common dermatoses with extremely variable clinical manifestations is commonly present as well defined erythematous scaly plaques which become silvery on an attempt to scrap. Various types of psoriasis include plaque or vulgaris, guttate, pustular, erythrodermic, flexural, palmo-plantar, arthritis and nails psoriasis [1].

Prevalence of psoriasis varies from $0.12-8 \%$ all over world population [2]. It is more in cold climate. It affects equally to male and female. It is seen in all age group; however when it occurs in early age group its association with HLA B57 and B13 is more. Remission and relapses are very common in psoriasis.

Various therapies used include topically coaltar [3], diathranol, corticosteroids with or without salicylic acid, calcipotriol [4], tazarotene and PUVA. Systemic therapies include [5] methotrexate [6,7], methotrexate +betamethasone [8], cyclosporine [9], PUVA, narrow band UVB, photo-therapy [10], hydroxyurea [11], azathioprine, retinoid like etretinate and acitretin [12-14] and biologics like etanercept and infliximabs [15]. All these treatment clear the psoriasis lesions partially or completely but are not able to prevent relapse or produce prolonged remission. Maximum remission period reported with these therapies is 1 year [16].

The chief problem in the management of psoriasis with various types of therapies is frequent relapses and subsequent need for repeated doses of systemic therapy leading to serious side effects. Repeated use of topical application usually leads to noncompliance by the patients.
The goal of psoriasis treatment should be to control the disease process initially; to decrease percentage of involved body surface area, to achieve and maintain remission for prolonged period or permanently, to produce minimum adverse side effects and to improve patient's quality of life.

Thus the need for more specific systemic therapy which targets the $\mathrm{T}$ lymphocyte with the promise of long term remission and less organ toxicities is needed.

\section{Precipitating factor in psoriasis}

Trauma in the form of burn, cut and scratch may produce and localized the lesions (Koebner's phenomenon).

Usually winter aggravates and summer improves the disease.

Infections: Bacterial infection especially streptococcal infection of upper respiratory tract, otitis media in children and infection in perianal area is associated with guttate psoriasis.

Drugs: Like chloroquine, beta-blocker and lithium are presumed

Correspondence to: Dr. Ramji Gupta, 47-C Pocket B Siddhartha Extension, New Delhi-110014, India, Tel: 91-11-26347405; E-mail: drramjigupta@yahoo.co.in

Key words: azathioprine, azathioprine pulse therapy, APT, prolonged remission, psoriasis

Received: August 20, 2015; Accepted: September 28, 2015; Published: October 03, 2015 
to precipitate psoriasis. Pustular psoriasis may be precipitated by atenolol, calcipotriol etc. Some workers implicate withdrawal of systemic corticosteroids as precipitating factor for pustular psoriasis.

Alcohol, emotional stress and smoking have doubtful effect on psoriasis.

\section{Associated diseases with psoriasis}

- No association has been seen with diabetes, skin cancers and liver diseases. Occasionally one may see glomerulo-nephritis with guttate psoriasis.

- Pulmonary fibrosis and renal amyloidosus may rarely occur in psoriatic arthropathy.

- Oral lesion in the form of geographical tongue and annular lesion are seen commonly in

pustular psoriasis.

\section{Pathogenesis of psoriasis}

Psoriasis is caused by activated T lymphocyte cells which secrete a particular set of cytokines. These cytokines promotes keratinocytes proliferation and accumulation of granulocytes.

\section{Genetic factor in psoriasis}

1. There is strong family association of the disease. Approximately $10-30 \%$ of patients of psoriasis have family history.

2. There is strong HLA association. A number of HLA like HLA B 13, B17, B57, cw6, cw7 and DR4 has been found associated with psoriasis. HLA Cw6 has been found to have largest risk for developing psoriasis.

3. Twin study shows $72 \%$ concordance for psoriasis in monozygotic twins but only $22 \%$ concordance in dizygotic twins.

\section{Locus of Gene in psoriasis}

Locus of gene for psoriasis is situated at distal end of the long arm of chromosome 17q. Other genes found on the distal end of chromosome $17 \mathrm{q}$ are CD7 (a T lymphocyte antigen found on peripheral $\mathrm{T}$ cells). ICAM-2, I-309 and IL enhancer gene. Recent studies suggest presence of psoriasis susceptibility locus in MHC region on 6p21 chromosomes and other chromosomes linkage on 2, 8 and 20. In another study it was found on $4 \mathrm{q}$ chromosome. All the above suggest that psoriasis has a polygenic inheritance.

\section{Environmental factors}

A variety of environmental factors has been implicated for development of psoriasis [17]. They are

1. Physical trauma present as koebner's phenomenon resulting from scratching, insect bite, surgery, excoriation and pyogenic infection causing damage to keratinocytes

2. Stress.

3. Drugs like antimalarial, beta blockers and lithium etc

4. Bacterial endotoxnis acts as super antigens which activates $\mathrm{T}$ lymphocytes and keratinocytes

\section{Immune mechanism in psoriasis}

Persistence spontaneous remission and exacerbation of psoriasis, linkage of HLA antigens strongly support immune-mechanism in psoriasis. Effectiveness of many immno-suppressive medicines like cyclosporine, methotrexate, corticosteroids, azathioprine and photo-chemotherapy points towards immune mechanism involved in production of psoriasis. Dysregulation of immune system and keratinocytes are also implicated. It is possible that activation of $\mathrm{T}$ lymphocytes and keratinocytes play a major role in the development of psoriasis [18-20].

\section{Role of T- lymphocytes (Antigen independent)}

In a genetically predisposed person, an injured keratinocytes synthesize and secrete a wide varieties of cytokines which include IL-I (which stimulate production of chemo-tactic cytokines and keratin proliferation), IL-6, IL-7, IL-8 (a potent T-cell and neutrophil chemotactant responsible for the formation of Munro's micro abscesses).

\section{Antigen dependent role to T-lymphocytes}

Continuous stimulation of $\mathrm{T}$ lymphocytes by super antigens leads to the release of various cytokines such as IL-2 and IL-8 which can directly stimulate keratinocytes proliferation and $\mathrm{INF}_{\mathrm{Y}}$. Keratinocytes in turn stimulate to secrete their own cytokines to maintain the psoriatic process. Due to prominent IL-2 and INFy and lack of IL-4 in psoriasis skin lesions, psoriasis is believed to be due to T helper type I cell cytokines.

Thus there are three changes accure in development of psoriasis

(A) Epidermal proliferation mediated by IL-1, IL-2, IL-6, IL-8, $\mathrm{TGF}_{\mathrm{x}}$ and INFy i.e. cell cycle of psoriasis shorten to 1.5 days from 13 days. Maturation and shedding reduce to 4 days from 26 days

(B) Increased dermal angiogenesis mediated by TGFx

(C) Munro's micro absess mediated by IL-8.

In short psoriasis is genetically determined $\mathrm{T}$ lymphocyte cell mediated disorder due to interaction between keratinocytes and $\mathrm{T}$ lymphocytes.

\section{Azathioprine}

Azathioprine is a purine antagonist [21] and convert rapidly into 6-mercaptopurine (6-MP) in vivo. To be effective as an immunesuppressive agent, 6-MP must be converted into its nucleotide, thioinosinic acid and other nucleotides that interfere with nucleic acid synthesis. Since azathioprine is a purine antagonist, it may inhibit DNA and RNA. Several studies have shown that azathioprine influences both humoral and cell immune functions in man and animal. In human, azathioprine suppresses antibodies production against various antigens, inhibits in vitro B-cell proliferation and diminishes T-cellmediated response. At higher concentration of azathioprine, the suppressor effects are the best.

Azathioprine is readily absorbed from the gastro-intestinal tract. Approximately 30\% azathioprine is bound to serum protein. Azathioprine is rapidly metabolized to a mixture of sulphur-containing metabolites. About 10 hours after the ingestion of azathioprine, most of it is found in the form of inorganic sulphate.

Very little intact azathioprine is excreted in human urine at the usual therapeutic dose.

Azathioprine has been used frequently in malignancies, air borne contact dermatitis, pemphigus, bullous pemphigoid, dermatomyositis, 
polymyositis, Behcet's syndrome, rheumatoid arthritis, systemic lupus erythematosus, renal transplantation, Crohn's disease and ulcerative colitis.

\section{Azathioprine in psoriasis}

In 1961 Kravetz and Balsam [22] first time used azathioprine in psoriasis. They used $2 \mathrm{mg} / \mathrm{kg}$ daily in 12 patients, $1-4$ courses with improvement. Majority of them developed relapse within 1.5-6 months after the last dose. In 1970 Greaves and Dauber [23] used $2.5 \mathrm{mg} / \mathrm{kg} / \mathrm{day}$ for 6 weeks in 10 patients with $25 \%$ clearance of the lesions in 5 patients in 2-6 weeks. Relapse was seen 1 month after stoppage of azathioprine. Feldges and Barnes in 1974 [24] used $2.5 \mathrm{mg} / \mathrm{kg} /$ day in 10 patients for 4.5 to 5.5 months with almost complete clearance of skin lesions in 6 patients. Azathioprine was discontinued after remission lasting for 1 year. However all developed relapse after stoppage of treatment. In $1974 \mathrm{Du}$ Vivier et al [25] used 100-300mg azathioprine daily for 2-24 weeks with $75-100 \%$ clearance of psoriasis lesions with maintenance dose of 75-200 mg daily in 13 out of 29 patients. One patient who was free of the lesions developed relapse 6 months after complete stoppage of azathioprine. Lee et al. [26] used 200-300 mg azathioprine daily for 12-24 months in psoriatic arthritis with improvement with few transient side effects. In a recent review in 2008 Halverstam and Lebwoh [27] reported usefulness of azathioprine in psoriasis quoting all the above work.

Thus all the above workers have reported beneficial results with azathioprine but most of them invariably reported relapse of psoriasis lesions after stoppage of azathioprine within 1-6 months.

Probably their dose of azathioprine and duration of treatment both were inadequate.

\section{Mechanism of action of azathioprine in psoriasis}

As psoriasis is caused by activated T.lymphocyte cells which produce cytokines. Cytokines lead to the proliferation of keratinocyctes responsible for development of psoriasis.

Azathioprine suppresses activated T lymphocyte cells which in turn stop production of cytokines leading to stoppage of proliferation of keratinocytes responsible for development of psoriasis.

\section{Azathioprine pulse therapy in psoriasis}

The term pulse therapy has been used for administering a large dose of drug over a very short period then withdrawing the drug completely till it is used again [28-31].

In 2003, author has started using an arbitrarily designed regimen of azathioprine which uses an intermittent high dose (IHD) azathioprine (500 mg on 3 consecutive days, repeated every month) in combination with continuous low dose (CLD) azathioprine (100mg orally daily) given in between IHD. Initially to clear the lesion fast methotrexate and topical coal tar was also used.

In 2008 author observed that a significant proportion of the patients initially treated with this regimen were in remission even after they stopped receiving treatment. The disease free duration in some cases was more than 3 years. Subsequently this regimen was used in almost all patients of psoriasis.

To achieve fast clearance of the lesion as well as prolong period of remission, this combination was proposed in the treatment of psoriasis.

Azathioprine was used in the form of Pulse Therapy i.e. $500 \mathrm{mg}$ on 3 consecutive days (IHD) to be repeated every month on the same date, with $100 \mathrm{mg}$ daily(CLD) in between the pulse. The regimen was divided into four phases. In phase I, treatment with IHD and CLD azathioprine was continued till clearance of psoriasis lesions. To clear the lesions fast, methotrexate (MTX) 15mg orally or subcutaneously or MTX $15 \mathrm{mg}+$ betamethasone (BMT) $3 \mathrm{mg}$ weekly was also given after breakfast. Topical coal tar/corticosteroids ointment with salicylic acid was also used wherever needed till the lesions clear completely and stopped recurring when it enters into phase II. In phase II, all the treatments was stopped except the azathioprine pulse(IHD) and daily azathioprine (CLD) which was given for another 9 months to stop any minor relapse. In the end of phase II, if there was no recurrence of lesions, azathioprine pulse(IHD) was also stopped and patients take only daily azathioprine $100 \mathrm{mg}$ for another 9 months to prevent even any minor relapse (phase III). In phase IV if there was no recurrence daily azathioprine was also stopped and patients were followed-up for any relapse.

High dose azathioprine for 3 days in a month is used to get its maximum effect on psoriasis by suppressing or neutralizing maximum cytokines and to reduce the side effects of daily high dose azathioprine.

Major apprehension with high dose and prolong use of azathioprine is toxicity; liver, bone and kidney but the various studies including this have shown no significant side effect even up to 200mg azathioprine used daily for 12 to 24 months and pulse azathioprine 1200-1800 mg used for 2-9 months. Side effects seen were only very transient which returned to normal in 3-4 weeks after stoppage of azathioprine without any recurrence when azathioprine was resumed again.

Seventy patients who completed the study (i.e. in phase IV) are in continous clinical remission since 1-10 years without any treatment. Thus azathioprine regimen shows prolonged remissions in patients with psoriasis and seems to have potential to cure the psoriasis. Subsequently it was found that this regimen has put the psoriatic joints and nail disorders also into prolonged remission [32,33].

Relapse: Five out of 9 patients who relapsed were given $2^{\text {nd }}$ course of APT after remission period of 9.5-28 months in phase IV, enter into remission and are in phase IV from 4--64 months.

\section{High Dose azathioprine pulse therapy}

Sandborn et al. [34] in 1995 used 1800mg azathioprine I.V. in 36 hours as loading dose in the treatment of 12 cases of Crohn's disease. Subsequently Durez and Horsemas [35] in 1999 used $40 \mathrm{mg} / \mathrm{kg}$ body weight azathioprine I.V. in 36 hours along with oral $2 \mathrm{mg} / \mathrm{kg} /$ day in ankylosing spondalysis. Pickenpack et al. [36] in 2000 used azathioprine $1800 \mathrm{mg}$ I.V. in 36 hours as loading dose along with $1-1.5 \mathrm{mg} / \mathrm{kg} /$ day for the treatment of 2 patients of rheumatoid arthritis, 3 cases of myositits with good result. There was no adverse reaction in all the above study. Maxavedan et al [37] in 2000 treated 9 patients of ulcerative colitis with 1200-2800 mg azathioprine I.V. given in 36 hours. In the last 3 patients they divided total dose of azathioprine into 3 doses of $800 \mathrm{mg}$ each given over 8 hours in 3 days. Two patients development transient 
leucopenia whereas one develop transient hepatotoxicity.

Benenson et al. [38] in 2004 used azathioprine in 4 patients of Wegener's granulomatosis and 2 patients of lupus nephritis, 1200-1800 mg I.V. in 24-36 hours. The dose was repeated every month for 2-9 months along with oral $100 \mathrm{mg}$ azathioprine. Aries et al. [39] in 2004 used in 2 patients of Wegener's granulomatosis $1200 \mathrm{mg}$ azathioprine I.V. over 24 hours.

\section{Side effect of azathioprine}

The main toxic effect of azathioprine is bone marrow depression, manifest most frequently by leucopenia, anemia, pancytopenia and thrombocytopenia. Severity is dose related [40].

Gastro-intestinal disturbances like nausea, vomiting and diarrhoea were noticed frequently. Other gastro-intestinal side effects reported are oral ulcerations, esophagitis with possible ulceration and steatorrhoea.

Hepatotoxicity in the form of liver enzyme changes has been occasionally reported.

In the study done by author reported above, the common side effects found were nausea and vomiting (18 patients), weakness and fatigue ( 4 patients), giddiness and restlessness ( 2 patients each), loss of appetite, sleeplessness and generalized malaise (1 patient each). Most of these side effects were seen in phase I and in patients in whom methotrexate was also used.

Liver function tests were elevated in 8 patients in phase I, 5 patients in phase II and 1 patient each in phase III and IV. These reverted back to normal 3 weeks after stopping azathioprine which was resumed again without any subsequent abnormalities. Transient leucopenia was seen in 3 patients, which returned to normal in 3-4 weeks after stopping treatment temporarily.

\section{Conclusion}

Azathioprine pulse therapy has the potential to clear the psoriasis for prolong period and probably to produce the permanent cure for life long if given properly.

\section{References}

1. Gupta R (2010) Miscellaneous disorders in Comprehensive Dermatology and Sexually Transmitted Diseases. New Delhi, Anne Books Pvt Ltd p178-182.

2. Gelfand JM, Stern RS, Nijsten T, Fiedman SR, Thomas J, et al. (2005) The prevalence of psoriasis in African Americans: results from a population based study. J Amer Acad Dermtol 52: 23-26. [Crossref]

3. Lebwohl M, Abel E, Zanlli M, Koo J, Drake L (1995) Topical therapy for psoriasis. Internat J Dermatol 34: 637-684.

4. Jain S, Sehgal VN (1997) Psoriasis and calcipotriol: an overview. Internat J Dermatol 36: 255-258. [Crossref]

5. Menter A, Korman NJ, Elments CA, Foldman SR, Gelfand JM, et al. (2009) Guidelines of care for the management and treatment of psoriasis with tradition systemic agents. $J$ Am Acad Dermatol 61: 451-485.

6. Roenigk HH Jr., Auerbach R, maiback HI, Weinstein GD (1988) Methotrexate in psoriasis: revised guidelines. J Am Acad Dermat 19: 145-156. [Crossref]

7. Morison WL, Momtaz K, Parrish JA, Fitzpatrick TB (1982) Combined methotraxtePUVA therapy in the treatment of psoriasis. J Am Acad Dermatol 6: 46-51. [Crossref]

8. Gupta R , Gupta Sarthak (2007) Methotraxate-betamethasone weekly oral pulse in psoriasis. J Dermatol Treat 18: 291-294. [Crossref]

9. Lebwohl M, Ellis C, Gottlieb A, Koo J, Kruer G, et al. (1998) Cycloporine consensus confrence with emphasis on the treatment of psoriasis. J Am Acad Dermatol 39: 464 475. [Crossref]
10. Morison WL (1999) Phototherapy \& photochemotherapy: an update. Sem Cut Med Surg 18: 297-306. [Crossref]

11. Moschella SL, Greenwald MA (1973) Psoriaisis with hydroxurea: An 18 month study of 60 patients. Arch Dermatol 107: 363-368.

12. Roenigk HH Jr (1999) Acitretin combination therapy. J Am Acad Dematol 41: S18-21. [Crossref]

13. Lebwohl M, Drake L, Mentar A, Koo J, Gotllieb AB, et al. (2001) Consensus conference, acitretin in combination with UVB or PUVA in treatment of psiaisis. $J$ Amer Acad Dermatol 45: 544-553.

14. Lebwohl M, Menter A, Koo J, Feldman SR (2004) Combination therapy to treat moderate to severe psoriasis. J Am Acad Dermatol 50: 416-430. [Crossref]

15. Antoni C, Manager B (2002) Infleximab for psoriasis and psoriatic arthritis. Clinical Exp Rheumat 20: S122-125. [Crossref]

16. Koo J, Lebwohl M (1999) Duration of remission of psoriasis therapies. J Am Acad Dermatol 41: 51-59. [Crossref]

17. Chandran V, Roychaudhary SP (2010) Geographical and environmental factors of psoriasis and psoriatic arthritis. J Autoimmune 34: 314-323. [Crossref]

18. Ortonne JP (1999) Recent developments in the understanding of the pathogenesis of psoriasis. Br J Dermatol 140: 1-7. [Crossref]

19. Nickoloff B J, Nestle F O (2004) Recent insights into the immuno-pathogenesis of psoriasis provide new therapeutic opportunities. J Clin Invest 113: 1664-1675. [Crossref]

20. Das RP, Jain AK, Ramesh V (2009) Current concepts in the pathogenesis of psoriasis Indian J Dermatol 54: 7-12. [Crossref]

21. Ahmed AR, Moy R (1981) Azathioprine. Int J Dermatol 20: 461-467.

22. Kravetz RE, Balsam T (1961) Treatment of psoriasis with mercaptopurine. Arch Dermatol 84: 597-600. [Crossref]

23. Greaves MW, Dawber R (1970) Azathioprine in psoriasis. Br Med J 2: 237-238. [Crossref]

24. Feldges DH, Barnes CG (1974) Treatment of psoriatic arthropathy with either azathioprine or methotrexate. Rheumat and Rehab 13: 120-124. [Crossref]

25. Du Vivier A, Munro DD, Vervor J (1974) Treatment of psoriasis with azathioprine. $B r$ Med $J$ 1: 49-51. [Crossref]

26. Lee JCT, Gladman DD, Schentag CT, Cook RJ (2001) The long-term use of azathioprine in patients with psoriatic arthritis. J Clinical Rheumat 7: 160-165. [Crossref]

27. Halverstam CP, Lebwohl M (2008) Nonstandard and off-label therapies for psoriasis Clinic Dermatol 26: 546-553. [Crossref]

28. Gupta R (2013) Azathioprine pulse therapy in the treatement of psoriasis. J Pakistan Associat of Dermatol 23: 120-125.

29. Gupta R (2013) Can we cure psoriasis? New Delhi, Prayatna 1-8.

30. Gupta R (2014) Prolonged remission of psoriasis with azathioprine pulse therapy. Apollo Medicine 11: 213-216.

31. Gupta R (2015) Prolonged remission of psoriasis with azathioprine pulse therapy Indian J Dermatol 60: 360-363. [Crossref]

32. Gupta R (2014) Azathioprine pulse therapy in the treatment of psoriatic arthritis: A case series. Apollo Medicine 11: 242-244.

33. Gupta R (2015) Azathioprine pulse therapy in the treatment of psoriasis nail: A case series. Apollo Medicine 12: 132-135.

34. Sandborn WJ, Van Os EC, Zins BJ, Tremaine WJ, Mays DC, et al. (1995) An intravenous loading dose of azathioprine decreases the time to response in patients with Crohn's disease. Gastroenterology 109: 1808-1817. [Crossref]

35. Durez P, Horsmas Y (2003) Dramatic response after an intravenous loading dose of azathioprine in one case of severe and refractory ankylosing spondylitis. Rheumatology 39: 182-184. [Crossref]

36. Pickenpack A. Straub RH Distler O, Hammond A, Oellerich M, et al. (2000) Safety and efficacy of an intravenous loading dose of azathioprine for treatment of non-TPMTdeficient patients with rheumatic diseases. Rheumatol 39: 1435-1436. [Crossref]

37. Mahavedan U, Tremaine WJ, Johnson T, Pike MG, Mays DC, et al. (2000) Intravenous azathioprine in severe ulcerative colitis: a pilot study. Am J Gastroenterol 95: 34633468. [Crossref] 
38. Benenson E, Fries JWU, Heiling B, Pollok M (2005) High-dose azathioprine pulse therapy as a new treatment option in patient with active Wegener's granulomatosis and lupus nephritis refractory or intolerant to cyclophosphamide. Clin Rheumatol 24: 251-257. [Crossref]
39. Aries PM, Hellmich B, Reinhold-Keller E, Gross WL (2004) High-dose intravenous azathioprine pulse treatment in refractory Wegener's granulomatosis. Rheumatol 43 : 1307-1308. [Crossref]

40. De Jong DJ, Goullet M, Naber TH (2004) Side effects of azathioprine in patients with Crohn's diseases. Eur J Gastroenterol Hepatol 16: 207-212. [Crossref]

Copyright: $\mathbb{C} 2015$ Gupta R. This is an open-access article distributed under the terms of the Creative Commons Attribution License, which permits unrestricted use, distribution, and reproduction in any medium, provided the original author and source are credited. 